\title{
PENINGKATAN KEMAMPUAN GURU DALAM MENYUSUN RENCANA PELAKSANAAN PEMBELAJARAN (RPP) MELALUI SUPERVISI AKADEMIK OLEH KEPALA SEKOLAH DI SD NEGERI 43 KOTA TERNATE TAHUN PELAJARAN 2017-2018
}

\author{
RUSNI H. ALI \\ Kepala SD Negeri 43 Kota Ternate, Jalan Ngofangare Soa, Ternate Utara, Kota Ternate, 97725 \\ Author Correspondence: rusni_hiali@yahoo.com \\ $\begin{array}{ll}\text { Diterima } & : 20-09-2019 \\ \text { Direvisi } & : 30-10-2019 \\ \text { Dipublikasi } & : 05-11-2019\end{array}$
}

\begin{abstract}
Abstrak: Pendidikan adalah salah satu upaya yang dilakukan untuk memperbaiki sumber daya manusia. Salah satu upaya yang dilakukan untuk memperbaiki sumberdaya manusia adalah dengan memperbaiki proses pembelajaran di sekolah. Proses pembelajaran dikelas dilaksanakan harus berdasarkan rencana yang telah disusun yang disebut Rencana Pelaksanaan Pembelajaran (RPP). RPP dari guru harusnya diperiksa oleh kepala sekolah. Karena salah satu tugas kepala sekolah adalah Supervisi akademik yang merupakan kegiatan terencana yang ditujukan pada aspek kualitatif sekolah dengan membantu guru melalui dukungan dan evaluasi pada proses belajar dan pembelajaran yang dapat meningkatkan hasil belajar. Salah satu materi yang disupervisi adalah Rencana Pelaksanaan Pembelajaran (RPP) . bagian dari perencanaan pembelajaran yang sangat penting dibuat oleh guru sebagai pengarah pembelajaran adalah Rencana Pelaksanaan Pembelajaran (RPP). Rencana Pelaksanaan Pembelajaran (RPP) adalah instrumen perencanaan yang lebih spesifik dari silabus. Rencana Pelaksanaan Pembelajaran ini dibuat untuk memandu guru dalam mengajar agar tidak melebar jauh dari tujuan pembelajaran. Hasil supervisi akademik terbukti secara ilmiah dapat meningkatkan kompetensi guru dalam menyusun RPP di SD Negeri 43 Kota Ternate. Ini terbukti dengan meningkatnya jumlah RPP guru yang baik dari dari siklus 1 ke siklus 2 , dengan peningkatan 31\% menjadi $83 \%$ setelah supervisi akademik.
\end{abstract}

Kata Kunci: Peningkatan kemampuan guru, supervisi akademik, RPP

\section{PENDAHULUAN}

Dalam meningkatkan kualitas sumberdaya manusia, guru mempunyai peran yang sangat penting karena kualitas guru merupakan salah satu variabel yang terpenting dalam menentukan kualitas pendidikan, khususnya yang berkaitan dengan kemampuan guru dalam membuat perangkat pembelajaran. Guru tidak hanya berfungsi mentransfer pengetahuan saja tetapi juga bertugas untuk memberikan keterampilan, merubah perilaku peserta didik. Untuk itu diperlukan guru yang profesional dalam pendidikan. Kompetensi guru harus terus menerus dibina dan dikembangkan sehingga guru mampu menghasilkan pendidikan yang bermutu. Kelemahan guru di sekolah bisa diatasi dengan kegiatan pengembangan kompetensi guru melalui supervisi akademik berkelanjutan oleh kepala sekolah. Dengan memaksimalkan kegiatan supervisi akademik diharapkan tenaga guru dapat meningkatkan pengetahuan dan keterampilan dalam proses pembelajaran. Supervisi akademik merupakan kegiatan terencana yang ditujukan pada aspek kualitatif sekolah dengan membantu guru melalui dukungan dan evaluasi pada proses belajar dan pembelajaran yang dapat meningkatkan hasil belajar.

Tujuan supervisi adalah memberikan layanan dan bantuan untuk meningkatkan kualitas mengajar guru di kelas yang pada intinya bertujuan untuk meningkatkan kualitas belajar siswa. Bukan saja memperbaiki kemampuan mengajar tetapi juga mengembangkan potensi kualitas guru (Sahertian, 2000:19). Dalam strategi pembelajaran terkandung tiga hal pokok yakni perencanaan, pelaksanaan dan evaluasi. Perencanaan program berfungsi untuk memberikan arah pelaksanaan pembelajaran sehingga 
menjadi terarah dan efisien. Salah satu bagian dari perencanaan pembelajaran yang sangat penting dibuat oleh guru sebagai pengarah pembelajaran adalah Rencana Pelaksanaan Pembelajaran (RPP). Rencana Pelaksanaan Pembelajaran (RPP) adalah instrumen perencanaan yang lebih spesifik dari silabus. Rencana Pelaksanaan Pembelajaran ini dibuat untuk memandu guru dalam mengajar agar tidak melebar jauh dari tujuan pembelajaran. Beberapa penelitian mengenai kemampuan guru dalam membuat perangkat pembelajaran menunjukkan beberapa implikasi pentingnya kemampuan dalam membuat atau menyusun perangkat pembelajaran sehingga terjadi perbaikan dan peningkatan terhadap proses belajar mengajar di kelas. Hasil temuan dari beberapa penelitian tersebut menunjukkan bahwa keterampilan dan pengetahuan guru dalam membuat atau menyusun perangkat pembelajaran khususnya RPP masih sangat rendah. Rendahnya kemampuan guru dalam menyusun atau membuat RPP memberikan dampak yang sangat buruk terhadap proses pembelajaran di kelas. Kinerja yang dapat dilihat oleh kepala sekolah hanyalah kehadiran tatap muka, tanpa mengetahui apakah kemampuan guru dalam mengelola pembelajaran sudah sesuai dengan harapan atau belum, atau sudahkah kompetensi dasar yang harus dikuasai oleh siswa terkuasai dengan benar.

Berdasarkan uraian latar belakang di atas, maka penulis tertarik untuk membahas pembinaan guru oleh kepala sekolah dengan judul penelitian Peningkatan Kemampuan Guru dalam menyusun Rencana Pelaksanaan Pembelajaran (RPP) oleh Kepala Sekolah Melalui Supervisi Akademik di SD Negeri 43 Kota Ternate Tahun Pelajaran 2017-2018. Menurut Glickman (1981: 110), mendefinisikan supervisi akademik adalah serangkaian kegiatan membantu guru mengembangkan kemampuannya mengelola proses pembelajaran demi pencapaian tujuan pembelajaran. Supervisi akademik merupakan upaya membantu guru dalam mengembangkan kemampuannya mencapai tujuan pembelajaran. Sehingga, esensi supervisi akademik itu sama sekali bukan menilai unjuk kerja guru dalam mengelola proses pembelajaran, melainkan membantu guru mengembangkan kemampuan profesionalismenya.

Tujuan supervisi akademik adalah membantu guru mengembangkan kemampuannya mencapai tujuan pembelajaran yang dicanangkan bagi murid-muridnya (Glickman, 1981: 60). Melalui supervisi akademik diharapkan kualitas akademik yang dilakukan oleh guru semakin meningkat. Pengembangan kemampuan dalam konteks ini janganlah ditafsirkan secara sempit, semata-mata ditekankan pada peningkatan pengetahuan dan keterampilan mengajar guru, melainkan juga pada peningkatan komitmen (commitmen) atau kemauan (willingness) atau motivasi (motivation) guru, sebab dengan meningkatkan kemampuan dan motivasi kerja guru, kualitas pembelajaran akan meningkat.

\section{METODE PENELITIAN}

Penelitian ini dilakukan dengan metode penelitian tindakan kelas yang berlangsung selama 2 siklus. Masing-masing siklus terdiri dari tahapan perencanaan, pelaksanaan, observasi dan refleksi. Metode penelitian yang dilakukan peneliti adalah dengan melaksanakan supervisi akademik yang meliputi supervisi tradisional dan supervisi klinis yang secara rinci dapat diuraikan sebagai berikut:

\section{Perencanaan Awal}

Langkah awal yang direncanakan pada penelitian tindakan sekolah ini terdiri dari beberapa kegiatan, yakni; (a) Identifikasi masalah; (b) Pengajuan proposal; dan (c) mempersiapkan instrumen.

\section{Siklus Pertama}

\section{a. Perencanaan}

Pada tahap ini, peneliti merencanakan langkah-langkah meliputi; (a) Mengidentifikasi jumlah guru yang sudah membuat RPP; (b) Meminta guru untuk mengumpulkan perangkat pembelajaran; (c) Peneliti memeriksa administrasi guru secara kuantitatif dan kualitatif; (d) Peneliti mengidentifikasi permasalahan yang ditemukan; dan (e) menyusun rencana tindakan (berupa penjadwalan supervisi individual atau kelompok disesuaikan dengan temuan pada identifikasi masalah) 


\section{b. Pelaksanaan}

Pada tahap ini peneliti melaksanakan tindakan supervisi individual/kelompok untuk menilai administrasi guru yang sudah dikumpulkan sebelumnya. Pelaksanaan supervisi dilakukan dengan pertemuan individual office-conference. Hal ini dilakukan terutama kepada guru yang tidak mengumpulkan perangkat pembelajaran, untuk mengetahui penyebab/masalahnya. Tahap ini peneliti rencanakan berlangsung selama 2 minggu dan dilaksanakan bersama-sama dengan kolaborator.

\section{c. Observasi}

Pada tahap ini peneliti melakukan kegiatan observasi terhadap seluruh kejadian yang terjadi selama tahap pelaksanaan dan mengobservasi hasil awal yang dicapai pada pelaksanaan tindakan siklus 1 . Selain itu peneliti juga mengidentifikasi masalah-masalah lanjutan yang timbul dari pelaksanaan tindakan di siklus pertama.

\section{d. Refleksi}

Pada tahap refleksi, peneliti melakukan evaluasi terhadap tindakan dan data-data yang diperoleh. Kemudian dilanjutkan dengan pertemuan bersama kolaborator untuk membahas hasil evaluasi dan penyusunan langkah-langkah untuk siklus kedua.

\section{Siklus kedua}

\section{a. Perencanaan}

Tahap perencanaan pada siklus kedua ini, peneliti melakukan pertemuan dengan kolaborator untuk menyusun penjadwalan supervisi kelas dan menyiapkan instrumen supervisi untuk siklus kedua.

\section{b. Pelaksanaan}

Pada tahap ini, guru-guru yang sudah siap perangkat perencanaanpembelajarannya disupervisi kelas oleh peneliti. Hal ini untuk melihat kesesuaian perencanaan pembelajaran dengan pelaksanaan pembelajaran.

\section{c. Observasi}

Di tahap observasi siklus kedua, peneliti mengobservasi kesesuaian perencanaan pembelajaran dengan pelaksanaan pembelajaran serta melihat keberterimaan siswa dalam proses belajar mengajar. Pada tahap ini pula, peneliti mengumpulkan data-data yang terjadi selama tahap pelaksanaan.

\section{d. Refleksi}

Pada tahap refleksi siklus kedua, peneliti melakukan evaluasi bersama guru yang disupervisi terhadap hasil observasi di siklus kedua.

\section{HASIL PENELITIAN}

Pada akhir semester ganjil tahun pelajaran 2017/2018, peneliti mencatat guru yang menyetorkan perangkat pembelajaran untuk ditandatangani. Hasil perhitungan perangkat pembelajaran yang dikumpulkan dapat dilihat pada tabel berikut.

Tabel 1. Rekapitulasi Guru Yang Menyetorkan Perangkat Pembelajaran

\begin{tabular}{ccccc}
\hline No & Komponen & $\begin{array}{c}\text { Jumlah } \\
\text { seharusnya }\end{array}$ & $\begin{array}{c}\text { Yang } \\
\text { mengumpulkan }\end{array}$ & \% \\
\hline $\mathbf{1}$ & Kalender Pendidikan & 6 & 6 & 100 \\
$\mathbf{2}$ & Program tahunan & 6 & 3 & 50 \\
\hline
\end{tabular}




\begin{tabular}{cllll}
\hline $\mathbf{3}$ & Program semester & 6 & 4 & 66 \\
$\mathbf{4}$ & KKM & 6 & 2 & 33 \\
$\mathbf{5}$ & Anasisil HE & 6 & 4 & 66 \\
$\mathbf{6}$ & Silabus & 6 & 5 & 83 \\
$\mathbf{7}$ & RPP & 6 & 3 & 50 \\
$\mathbf{8}$ & Daftar hadir siswa & 6 & 4 & 66 \\
$\mathbf{9}$ & Daftar nilai & 6 & 4 & 66 \\
$\mathbf{1 0}$ & Analisis hasil ulangan & 6 & 3 & 33 \\
\hline
\end{tabular}

Dari tabel di atas jelas terlihat bahwa data dasar guru yang menyusun RPP adalah sebesar 50\%. Dari RPP yang terkumpul ini, kemudian penulis melakukan penelaahan terhadap kualitas dari perangkat pembelajaran yang dikumpulkan terutama pada RPP. Data yang diperoleh dari penelaahan tersebut dapat digambarkan pada tabel kualitas RPP SD Negeri 43 pada sub berikut.

\section{Kualitas RPP Guru Tahun Pelajaran 2017/2018}

Kualitas RPP yang dibuat oleh guru SD Negeri 43 Ternate secara umum dapat dikatakan kurang baik. Hal ini dikarenakan masih banyak RPP yang terkesan tidak original (copy paste dari orang lain). Hal ini terlihat dari tidak timbulnya visi dan misi serta tujuan sekolah pada RPP yang dibuat oleh guru. Secara lebih jelas berikut penulis gambarkan hasil penilaian penulis terhadap kualitas RPP 6 orang guru SD Negeri 43 Ternate tahun pelajaran 2017/2018.

Tabel 2. Daftar Nilai Kualitas RPP Tahun Pelajaran 2017/2018

\begin{tabular}{clcc}
\hline No & \multicolumn{1}{c}{ Nama Guru } & RPP & \% \\
\hline $\mathbf{1}$ & Fatma Thalib,S.Pd & 72 & 72 \\
$\mathbf{2}$ & Siti Aisyah Hanafi,S.Pd & 71 & 71 \\
$\mathbf{3}$ & Suryani Zakaria,S.Pd & 60 & 60 \\
$\mathbf{4}$ & Maryam Hasan,S.Pd & 65 & 65 \\
$\mathbf{5}$ & Nurmala Suminta & 60 & 60 \\
$\mathbf{6}$ & Saiyah,S.Pd & 60 & 60 \\
\hline
\end{tabular}

Dari tabel di atas, jelas terlihat bahwa kualitas RPP guru SD Negeri 43 Ternate pada tahun pelajaran 2017/2018 masih sangat rendah. Dari 6 orang guru yang RPP-nya dianalisa oleh peneliti, guru yang memiliki RPP yang bernilai baik hanya 2 orang guru atau $33 \%$.

\section{Kompetensi Guru dalam menyusun RPP setelah siklus ke-1}

\section{Kuantitas Guru yang menyusun RPP setelah siklus ke-1}

Pada rapat awal tahun pelajaran 2017/2018, peneliti memerintahkan kepada seluruh guru untuk membuat perangkat pembelajaran. Setelah berjalan selama hampir satu bulan, peneliti mengumumkan kepada seluruh guru bahwa pada bulan Agustus 2017 akan dilakukan supervisi terhadap administrasi guru.

Pada siklus ini seluruh guru diminta untuk mengumpulkan perangkat pembelajaran tersebut. Selanjutnya peneliti melakukan analisis dan penilaianterhadap kuantitas guru yang menyetorkan perangkat pembelajaran terutama RPP. Dari hasil perhitungan peneliti terhadap jumlah guru yang mengumpulkan RPP didapatkan data sebagai berikut. 
Tabel 3. Rekapitulasi Perhitungan Pengumpulan RPP Pada Siklus 1

\begin{tabular}{lcccc}
\hline No & Kelas & \multicolumn{3}{c}{ RPP } \\
\cline { 3 - 5 } & & Seharusnya & $\begin{array}{c}\text { Yang } \\
\text { dikumpulkan }\end{array}$ & $\%$ \\
$\mathbf{1}$ & I & 6 & 5 & 50 \\
$\mathbf{2}$ & II & 6 & 4 & 66 \\
$\mathbf{3}$ & III & 6 & 5 & 83 \\
$\mathbf{4}$ & IV & 6 & 4 & 66 \\
$\mathbf{5}$ & V & 6 & 3 & 50 \\
$\mathbf{6}$ & VI & 6 & 2 & 33 \\
\hline
\end{tabular}

Dari data jumlah guru yang mengumpulkan RPP pada awal siklus1, dapat terlihat bahwa dengan informasi adanya supervisi akademik terhadap guru dapat meningkatkan kuantitas jumlah guru yang menyusun RPP yang sebelumnya hanya $50 \%$, mengalami peningkatan kuantitas menjadi $64 \%$.

\section{Kualitas RPP setelah siklus ke-1}

Sebelum melakukan supervisi individual terhadap seluruh guru terutamakepada guru yang belum menyetorkan RPP. Peneliti melakukananalisa kedua terhadap sampel RPP yang dibuat oleh guru. Hasil analisis kualitas RPP tersebut dapat terlihat pada tabel berikut.

Tabel 4. Penilaian RPP Pada Siklus 1

\begin{tabular}{clcc}
\hline No & Klasifikasi & Rentang nilai & \% \\
\hline $\mathbf{1}$ & A: Baik Sekali & $86-100$ & 0 \\
$\mathbf{2}$ & B :Baik & $71-85$ & 22 \\
$\mathbf{3}$ & C : Cukup & $51-70$ & 67 \\
$\mathbf{4}$ & D: Kurang & $0-50$ & 0 \\
\hline
\end{tabular}

Hasil analisa kualitas penyusunan RPP setelah dilakukan supervisi individual (setelah direvisi) dapat dilihat pada uraian berikut.

\section{Kompetensi guru menyusun RPP setelah siklus ke-2}

Pada siklus kedua ini, penelitian dilanjutkan dengan menganalisa/menguji keaslian RPP yang disusun oleh guru. Metode yang digunakan adalah dengan melakukan supervisi kelas..Hasil dari analisa tersebut, menunjukkan bahwa RPP yang dikumpulkan benar disusun oleh guru yang bersangkutan. Karena terjadi kesesuaian skenario antara perencanaan dan pelaksanaan di kelas.

\begin{tabular}{clcc}
\multicolumn{4}{l}{ Tabel 5. Hasil Penilaian Supervisi Kelas } \\
\hline No & Klasifikasi & Rentang nilai & \% \\
\hline $\mathbf{1}$ & A: Baik Sekali & $86-100$ & 0 \\
$\mathbf{2}$ & B :Baik & $71-85$ & 83 \\
$\mathbf{3}$ & C : Cukup & $51-70$ & 17 \\
$\mathbf{4}$ & D: Kurang & $0-50$ & 0 \\
\hline
\end{tabular}

Dari hasil perhitungan pada tabel di atas, maka dapat ditarik sebuah kesimpulan bahwa RPP yang dikumpulkan guru adalah bersifat original. Hal ini terlihat dengan cukup besarnya guru mampu melaksanakan pembelajaran sesuai dengan rencana yang dibuat. 


\section{KESIMPULAN}

Berdasarkan hasil penelitian, dapat kami simpulkan sebagai berikut:

1. Supervisi akademik terbukti secara ilmiah dapat meningkatkan kompetensi guru dalam menyusun RPP di SD Negeri 43 Kota Ternate. Ini terbukti dengan meningkatnya jumlah RPP guru yang baik dari $31 \%$ menjadi $83 \%$ setelah supervisi akademik.

2. Langkah-langkah yang mengakibatkan terjadinya peningkatan kompetensi guru dalam menyusun RPP tersebut meliputi; (a) Pengumuman rencana supervisi terhadap guru, dan (b) Pelaksanaan supervisi individual, dimana setiap guru diminta mempresentasikan RPP-nya kepada kepala sekolah, kemudian kepala sekolah memberikan masukan terhadap kekurangan RPP guru.

Untuk mengecek originalitas RPP yang disusun guru, kepala sekolah melakukan supervisi kelas. Hal ini dilakukan untuk menyesuaikan rencana yang dimuat dalam RPP dengan penerapannya di kelas. Jika sesuai, maka dapat dipastikan, kompetensi guru dalam menyusun RPP tersebut benar (bukan jiplakan atau dibuatkan orang lain). Jika banyak ketidaksesuaian maka ada kemungkinan RPP tersebut dibuatkan oleh orang lain. Peningkatan kompetensi guru dalam menyusun RPP sudah baik, dengan dibuktikan peningkatan dari $33 \%$ menjadi $83 \%$.

\section{DAFTAR PUSTAKA}

Ahmad Ashari, Supervisi Rencana Program pembelajaran, Jakarta 2004

Anwar, Moch. Idochi. 2004. Administrasi Pendidikan dan ManajemenBiaya Pendidikan. Bandung: Alfabeta

Depag RI Direktorat Kelembagaan Islam, pedoman Pengembangan Administrasi dan Supervis Pendidkan, Jakarta 2004

Depdiknas. 1997. Petunjuk Pengelolaan Adminstrasi Sekolah Dasar.Jakarta: Depdiknas.

Depdiknas. 2001. Manajemen Peningkatan Mutu Berbasis Sekolah.Jakarta: Depdiknas.

Depdiknas. 2010. Supervisi Akademik; Materi Pelatihan PenguatanKemampuan Kepala Sekolah; Jakarta: Depdiknas.

Harahap, Baharuddin. 1983. Supervisi Pendidikan yang Dilaksanakan olehGuru, Kepala Sekolah, Penilik dan Pengawas Sekolah. Jakarta: DamaiJaya

Majid, Abdul. 2005. Perencanaan Pembelajaran: MengembangkanStandar Kompetensi Guru. Bandung: PT Remaja Rosdakarya.

Muhaimin (2004). Paradigma Pendidikan Islam. Bandung: PT RemajaRosdakarya.

Mulyasa, E., 2003. Kurikulum Berbasis Kompetensi: Konsep,Karakteristik, dan Implementasi. Bandung: PT Remaja Rosdakarya

Sahertian, Piet A. 2000. Konsep-Konsep dan Teknik Supervisi PendidikanDalam Rangka Pengembangan Sumber Daya Manusia. Jakarta: RinekaCipta.

Sapari, Achmad. 2002. Pemahaman Guru Terhadap Inovasi Pendidikan.Artikel. Jakarta: Kompas (16 Agustus 2002).

Supandi. 1996. Administrasi dan Supervisi Pendidikan. Jakarta:Departemen Agama Universitas Terbuka.

Suprihatin, MD. 1989. Administrasi Pendidikan, Fungsi dan TanggungJawab Kepala Sekolah sebagai Administrator dan Supervisor Sekolah.

Semarang: IKIP Semarang Press.Surya, Muhammad. 2003. Psikologi Pembelajaran dan Pengajaran.

Bandung: Yayasan Bhakti WinayaSuryasubrata.1997. Proses Belajar Mengajar di Sekolah. Jakarta: RinekaCipta.

Usman, Moh. Uzer. 1994. Menjadi Guru Profesional. Bandung: PTRemaja Rosdakarya.

Wahidin; 13 Faktor untuk menjadi Kepala Sekolah Yang Efektif, 2008

Wardani, IGK. 1996. Alat Penilaian Kemampuan Guru (APKG). Jakarta:Dirjen Dikti. 